\title{
Food Safety Implementation in the Perspective of Network Learning
}

\author{
Zam-Zam Abdirahman ${ }^{\mathrm{a}}$, Leslie D. Bourquin ${ }^{\mathrm{b}}$, LoḮ Sauvée ${ }^{\mathrm{a}^{*}}$, And Deepa \\ THIAGARAJAN ${ }^{\mathrm{b}}$ \\ ${ }^{a}$ INTERACT Research unit, UniLaSalle, 60000 Beauvais, France \\ b Department of Food Science and Human Nutrition, Michigan State University, Michigan, USA \\ * Corresponding author \\ loic.sauvee@unilasalle.fr
}

Received: 5 June 2017; Published online: 18 October 2018

\begin{abstract}
The food sector frequently faces difficulties in implementing food safety standards. Indeed, there are many barriers to appropriation of quality management standards which make effective implementation difficult for small and medium enterprises (SMEs), such as limited access to information, lack of financing and cognitive resources, food hazard perception, and insufficient access to adequately trained personnel. Consequently, one fundamental objective for practitioners such as managers, public bodies and development agencies is to help these food SMEs in improving their implementation capacity, which is usually done through the launch of different forms of collective initiatives such as associations, clubs, learning platforms, regional actions and other forms of collaboration. Globally speaking, the objective of these initiatives typically is to develop a step by step approach providing guidance on good practices associated with the implementation of these systems. The objective of the article is to explore and test the validity of this hypothesis, rooted in a general idea of "organizational network learning": the capacity of SMEs to adopt new food safety schemes is seen as a whole and necessitates mobilizing, at the same time, 1) formal innovation networks, which bring cognitive resources and institutional credibility, and 2) the practice by managers of informal network activities through interactive exchanges of information, benchmarking, knowledge transfer and translation, and experiential learning.
\end{abstract}

Keywords: Food safety; Implementation; Learning; Network; SME

\section{Introduction}

In modern agrifood systems, the development and effective implementation of food safety and quality management system standards (hereafter FSMS) such as ISO 22000, BRC (British Retail Consortium), IFS (International Food Standard) and other similar management standards is crucial (Scott \& Chen, 2010). The food sector, mainly composed of SMEs, frequently faces difficulties in implementing these standards. Indeed, there are many barriers to appropriation of quality management standards which make effective implementation difficult for SMEs, such as limited access to information, lack of financing and cognitive resources, food hazard perception, and insufficient access to adequately trained personnel (Trienekens \& Zuurbier, 2008).

Consequently, one fundamental objective for practitioners such as managers, public bodies and development agencies is to help these food SMEs in improving their implementation capacity, which is usually done through the launch of different forms of collective initiatives such as associations, clubs, learning platforms, regional actions and other forms of collaboration (Abdirah- 
man \& Sauvée, 2012; Geith, Vignare, Bourquin, \& Thiagarajan, 2010; Mensah \& Julien, 2011; Trienekens \& Zuurbier, 2008). Globally speaking, the objective of these initiatives typically is to develop a step by step approach to identify the benefits of engaging its members in food quality management programs and providing guidance on good practices associated with the implementation of these systems. More specifically, these initiatives aim to address the following tasks: the enhancement of the awareness in food quality management principles; the selection of adequate and competent partners such as consultants and coaches; the mobilization of the relevant services; the efficiency of the overall coordination over time; and the implementation of some global managerial recommendations. Nevertheless, the underlying hypothesis of these collective initiatives is rarely adressed, nor is it analyzed and compared in a systematic way. This hypothesis is rooted in a general idea of "network learning": the capacity of SMEs to adopt new food quality management schemes is seen as a whole and necessitates mobilizing at the same time, the following: a) formal innovation networks, which bring cognitive resources and institutional credibility, and b) the practice by managers of informal network activities through interactive exchanges of information, benchmarking, knowledge transfer and translation, and experiential learning.

In this context, the aim of this article is threefold. Firstly, it is to craft an original analytical framework in line with the literature on innovation networks, managerial innovation, network learning and related learning effects, specifically devoted to the study of quality management standards appropriation and implementation. This first part is mainly devoted to the identification of three categories of so called "network effects" that are provided by collective initiatives. The second objective of this article is to apply this framework to specific collective initiatives conducted in two countries (USA and France) in order to identify and compare the key relevant network effects induced at SME level by these collective initiatives which occur during the process of FSMS implementation by the involved SMEs. Thus, the research will identify strengths and weaknesses of these initiatives using a com- mon grid based upon sound theoretical foundations. Indeed, a better understanding of learning processes at the individual as well as collective levels, both in informal (interpersonal) and formal (organizational) relationships, will providing insights into the major relevant learning principles and their possible adaptation to specific agrifood system sectors and to different national or regional contexts. Finally, we propose some concluding comments about the managerial implications derived from this analysis.

\section{Materials and Methods}

Yin (2013) case study methodology is followed. The case study is selected with an objective of an analytic generalization and comparison between cases. This approach of analytic generalization is relevant when "a previously developed theory is used as a template with which to compare the empirical result of the study". The research protocol in such an approach is based on interviews, which according to Eisenhardt and Graebner (2007) is a rich source of information and well adapted when the phenomenon is complex or unknown. Thus, several face-to-face interviews were conducted. In practice, the data was collected from a questionnaire and processed manually. Data collection is carried out among four actors: network coordinator, SMEs (adherents and beneficiaries of the network), public body and consultants (experts). Interviews with SMEs focused on a number of areas including membership motivations and network contributions. In total, seven semi-structured interviews were conducted: one with the network coordinator (CCI representative), one with the training organization, one with a consultant of quality and four with SMEs. The interviewees within the SMEs were the CEO (three interviews) and a quality referent (one interview). The consultant followed the company for a period of six months in order to realize a diagnosis, implement an action plan and monitor the implementation of the action plan. The training organization, meanwhile, carried out collective training for all companies of the collective.

This information was augmented by secondary data about the environment, the quality proce- 
dures and the market characteristics relevant to the case study. The research protocol was conducted by the authors and based on extensive discussions with all members of the initiatives. More specifically, the two case studies followed a strict protocol, with iterative interviews of all the participants of the initiatives, and completed with interviews of the SMEs involved in the initiatives through contact with their CEOs and quality managers.

\section{$3 \quad$ Results and Discussions}

\subsection{Network effects in Food Safety Management Standard (hereafter FSMS) implementation: emphasizing the interests of collective initiatives}

Based upon a literature review, we considered three categories of network effects that are relevant to the topic. These effects are categorized as follows (Abdirahman \& Sauvée, 2012):

1. The structural effect which finds its roots mainly in the structural analysis of networks;

2. The interactive effect which more specifically questions the idea of a networking activity that will support the implementation process;

3. The cognitive effect which focuses on the impact of the time dimension on any networking activity, leading to irreversibility, to path dependency and to the accumulation of new and specific knowledge useful for implementation of FSMS.

\subsection{Exploring the structural dimensions of collective initiatives}

For (Conway \& Steward, 1998, 2009), the network perspective applied to innovation research has considerably renewed and extended our knowledge of innovation processes across different categories of innovation, including technological as well as marketing and organizational innovations. The starting point of the process of structural analysis is to consider any collective initiative, seen as a network, as a combination of actors and relationships (Burt, 2000; Borgatti \& Li, 2009). In the structural analysis of networks, the actors are not independent but rather interdependent and influence each other. To take into account the unique situation of each member and the network structure as such, the structural approach combines two complementary perspectives: the global network, that is to say its density, the average distance between each of its members and the existence of subsets more or less structured; and the ego network, that is to say the situation of an actor (an individual, a SME) in its environment, its degree of inclusion and its mode of insertion into the global network (Borgatti \& Li, 2009, 2009; Coulon, 2005). Another point to be considered is the evolution over time of the structural aspects of global and ego networks, which reinforces the importance of phases in FSMS implementation. Actors are considered as nodes, and relationships between them as ties. Thus, research on innovation, which mobilizes the structural analysis of networks (Coulon, 2005), produces a representation of innovation processes as maps (Conway, Jones, \& Steward, 2001) or charts of nodes and relationships.

Consequently, within the FSMS context, two families of components must first be identified: actors and relationships. The identification of relationships that these actors have with one another is the second component. In line with social network theorists, these relationships can be of several types: continuous (similarities, relationships, interactions, such as common physical locations and cultural similarities) or discrete (financial flows, knowledge flows, such as permanent exchange of information), directed or not, measured by value or not, and formal or informal (Borgatti \& Li, 2009). The systematic process of implementing management system standards such as FSMS typically involves two groups of major actors (Abdirahman, Kisempa Muyuala, \& Sauvée, 2013; Hatanaka, Bain, \& Busch, 2005; Hatanaka, Bain, \& Busch, 2006): individuals 
(managers and consultants) and organizations (SMEs, standardization bodies such as ISO, the International Organization for Standardization, consular agencies, auditors, governmental bodies and banks). Finally, the network reveals itself, by its structural properties, as facilitating (or hindering) the implementation.

\subsection{Networking activity within collective initiatives}

When implementing FSMS principles, knowledge transfer to the organization necessitates the mobilization of new cognitive resources and the activation of formal structures. An analytical approach applied to the implementation of FSMS is, therefore, assumed to provide a better understanding of the necessary learning processes. For Boris, Sandra, and Isabelle (2007), the mechanistic perspective is an essential step in that "the transfer of knowledge, considered as the dependent variable, proceeds from an optimal layout between the nature of network and the types of knowledge. The question is often that of a systematic identification of structural and relational properties of the network, as brakes or levers of the knowledge transfer." However, this structural determinism cannot alone explain the implementation process. Implementing FSMS implies a set of interdependencies and a permanent adjustment between the actors, their objectives and the context in question. Thus emerges a vision of co-constructed knowledge. In the end, a more complete representation of the relationship between network and organizational learning should show that the network is a "channel for learning but, recursively, that the network is transformed by the learning taking place. In other words, the network is at least partly constructed by the learning processes, dynamically, deliberately and in an emergent manner" (Boris et al., 2007).

The ambivalent dimension of the network in the phenomena of innovation is demonstrated by Owen-Smith and Powell (2004), Powell, Koput, and Smith-Doerr (1996), Powell, White, Koput, and Owen-Smith (2005) and Conway and Steward (2009). By distinguishing the network itself from the networking event, they show that the study of the innovation process involves taking into account both the structural dimension and interactivity. For Conway and Steward (2009), there is an interaction between the network as a structure and the networking event taking place in this network, with "on the one hand, the network may constrain or liberate the patterns of interaction and exchanges between network members; on the other, networking behavior may serve either to ossify (i.e. fix) the existing network membership and relationships, or create a dynamic in the membership and relationships within the network" (Conway \& Steward, 2009). In the FSMS context, mobilizing transfers of knowledge, social networks and learning processes are involved. Thus, "the formal structure of network, but also the quality and relational characteristics that are played out, have a role on the nature of the learning that occurs there" (Boris et al., 2007). According to these authors, simultaneous consideration of structural and relational dimensions are necessary, in part, due to the fact that the individual is demanding of both resources and information but also demands a sense of belonging and social ties.

\subsection{Collective initiatives as drivers of cognitive resources}

The implementation of a FSMS goes through qualitatively distinct stages (Henson \& Humphrey, 2009, 2010) with an evolutionary perimeter of actors involved in the process. These steps are mostly a reflection of the types of actors mobilized and of their changing status or role from one phase to another. Therefore, it is necessary to consider explicitly the time dimension and its corollary, namely its influence over the types of actors involved, and over the process of adopting the FSMS. This reflects the fact that the implementation is done in the long run and differentially mobilizes actors and resources. More precisely the time dimension in FSMS implementation impacts on the degree and number of involved SMEs and partners, with the idea of threshold effects: as soon as a threshold is reached, for instance in terms of number of consultancy firms involved in the initiative, a new stage of development is 
possible.

The corollary of such a time dimension in the long run is the impact of knowledge creation and accumulation. Consequently, the implementation of a FSMS within a company, with its deep impacts on organizational structures and management procedures, requests an original view of the combination between the implementation process and learning phenomena. Change in organization related to learning is an important body of literature, stemming mainly from the seminal works of Argyris and Schön (1996) and Levitt and March (1988). According to Pawlowsky (2001) and his extensive survey of literature on learning, it is clear that "there are distinct perspectives on organizational learning that differ in respect to certain basic assumptions"; nevertheless, this author suggests that it is possible "to see outlines of a picture that visualizes basic building stones of an integrative model of organizational learning". His review suggests four different dimensions of learning: system-levels (from individual to network), learning modes (cognitive, cultural, action), learning types (single-loop, double-loop, deutero) and phases (Dierkes, Antal, Child, \& Nonaka, 2003).

Following Podolny and Page (1998) and authors in social capital theory (Burt, 2000; Inkpen \& Tsang, 2005; Nahapiet \& Ghoshal, 1998), we will identify some characteristics of these cognitive effects that are paramount in the understanding of FSMS implementation. The basic idea for these effects is the fact that at a certain period of its development, learning processes lead to different forms of institutionalization within a formal network, which thus become a kind of "institution", producing its own rules, norms, values and culture, and aspects themselves embedded in idiosyncratic resources and skills. In the terms of Powell et al. (1996), the network becomes progressively the "locus of innovation".

\subsection{Network effects in FSMS implementation: synthesis and managerial implications from a collective initiative point of view}

The approach developed of FSMS implementation is the delineation of the structural characteristics of network, of the characteristics of the networking activity and of the network seen as a source of specific cognitive resources (Abdirahman \& Sauvée, 2012). We have seen that this idea of three categories of network effects finds its source in the social capital theory (Burt, 2000; Nahapiet \& Ghoshal, 1998; Inkpen \& Tsang, 2005) and has already been developed in the context of innovation in general (Zheng, 2010) and managerial innovations in particular (Pitsis, 2013). Nahapiet and Ghoshal (1998) for instance define social capital as the sum of the actual and potential resources embedded within, available through, and derived from the network of relationships possessed by an individual of a social unit, it comprises both the network and the assets that may be mobilized through that network". As suggested by Pittaway, Robertson, Munir, Denyer, and Neely (2004) and Conway and Steward (2009), the connection has been made between the benefits of network and innovation. But the literature on the role and functions of networks on innovation can be approached through at least two interpretations (Conway \& Steward, 2009). In the first one, the network is seen as a new way of organizing innovation activities, between market and hierarchy: it is thus the governance aspect that is emphasized. In the second one, the network is not considered per se as a specific mode of organizing activities benefiting (or not) to innovation. Instead, it is viewed as a new analytical lens which is interesting to focus on because it produces a wide range of effects, of externalities, that will influence the innovation processes. Doing so, the network is tracked via the effects it may produce, as a phenomenon affecting behavior of individuals and companies.

For instance, interaction effects between individuals probably will be more important at early stages of the implementation processes, while 
structural dimensions are more predominant in well-established network relationships. Finally, cognitive effects will be mainly related to the institutionalization of a formal innovation network, especially when it becomes formalized into rules, routines and procedures which also tend to create path dependency, organizational memory and common resources. Through two examples in the USA and in France, we will show the nature of these effects and the necessary conditions under which these collective initiatives may be beneficial to SMEs.

\section{Case study of collective initiatives for FSMS implementation in the USA and France}

\subsection{In the USA (with global implementation): the Food Safety Knowledge Network developed by Michigan State University (MSU)}

Beginning in 2008 and in collaboration with several international partners, Michigan State University launched the Food Safety Knowledge Network (FSKN) initiative (Geith et al., 2010). The overall objectives of the FSKN initiative are to

1. develop internationally recognized competences in relation to food safety for individuals at all levels and in all sectors of the food supply chain, and

2. promote knowledge transfer within the food safety community.

The FSKN achieves these aims by harmonizing existing technical food safety training schemes through the development of the competencies of food safety professionals, recognized by international stakeholders, both from the public and the private sectors.

The FSKN is a collaborative platform that provides free access to high-quality, standardized learning resources in a highly scalable manner. To that end, all content (cognitive resources) is shared on the internet as Open Educational Resources (OER) under Creative Commons licensing via the FSKN web portals. The FSKN uses open source tools and openly-licensed materials encouraging development of derivative works that only require attribution to source and sharing under similar license as standardized FSKN content. This approach enables other users to customize, translate, and localize content for specific audiences or sectors of the food industry, and share these derivative works through either the MSU FSKN portals or their own web sites. Beyond content development, the FSKN initiative utilizes formalized training delivery mechanisms (e.g. face-to-face training, eLearning, blended learning) as well as coaching and mentoring of participants on effective strategies for implementing food safety management systems. The FSKN approach has been pilot-tested in a number of countries in collaboration with numerous partners from the food industry (individual companies and associations), development agencies, academic institutions and other service providers (Heyboer, Kim, Bourquin, \& Thiagarajan, 2010). The specific approach has varied somewhat from country to country, but in general the target audience for capacity development has been small-and medium-scale suppliers (both primary producers and food processors) who are seeking to execute sales contracts with multi-national food retailers or other highvalue markets within their country, or to engage in regional or distant trade of their products to more discriminating markets. Gaining access to these higher-value markets (both domestic and export) requires the suppliers to reach a much higher level of sophistication with respect to food safety and quality management systems, and ultimately the execution of sustainable contracts in these markets requires certification of the food safety management systems that are being implemented by these suppliers against recognized international standards. 


\section{Organizational level}

The FSKN project engages a wide variety of organizations in accomplishing its mission. As the leader of the FSKN initiative, Michigan State University (MSU) and the faculty leading the effort are principally focused on the creation and transmission of knowledge to improve the competitiveness of primary producers (i.e. farmers) and SMEs in less-developed countries. Beyond improving food safety systems implemented by these suppliers, another long-range objective of these efforts is to improve the livelihoods of farm families and front-line workers in these less developed businesses.

Content development in the FSKN initiative is guided by international standards, with programs being delivered on international food safety guidelines adopted by the Codex Alimentarius Commission managed by the Food and Agricultural Organization of the United Nations (which are recognized as the de minimis food standards in member countries of the World Trade Organization) and other programs focused on helping suppliers meet the expectations of international private food safety standards such as those benchmarked by the Global Food Safety Initiative (GFSI). Individuals from several GFSImember companies have participated in content development for the FSKN since its inception, and engagement with public sector food standards representatives (e.g. UN agency representatives or individual governments) has been encouraged where possible.

Content delivery in the FSKN project typically has been conducted by MSU researchers in partnership with academic institutions based in the countries where training occurs. The partner academic institutions are essential to the effective delivery of the content for local clientele because of the ability to deliver the training and mentoring in local language(s) and also because of their capabilities to localize the content with respect to local practices and cultural norms. It is preferable for MSU to work with local academic institutions in this manner as they share a similar culture of academic inquiry and knowledge dissemination. These collaborations also have a high likelihood of sustainability over the longer term.
The beneficiaries of the capacity development (e.g. farmers or processing establishments and their employees) may self-select for participation in these capacity development programs, but more commonly they are identified as potential or existing suppliers for multinational companies (either for the domestic market or export) who are in need of training and mentoring on the development and implementation of internationally-recognized food safety management systems. Many of the participating beneficiary farmers or manufacturers also are members of cooperatives or other food industry associations, which often work collectively to address key challenges such as compliance with food safety and quality standards. The multinational companies are motivated to identify suppliers for participation in these programs for a variety of reasons, but chiefly it is to help ensure the overall safety and quality of products sourced from these suppliers and, therefore, serves to protect the brand of these multinationals.

A variety of service providers also have engaged in the FSKN project since its inception. These have included third-party certification bodies who provide food safety certification, organizations offering food traceability support, equipment suppliers, sanitation services organizations, chemical suppliers, and providers of other ancillary services to farms or food processors.

Finally, several donor organizations, UN organizations and other NGOs have participated in or contributed to the FSKN initiative since its inception. Donor organizations such as the United States Agency for International Development (USAID) and the World Bank have provided financial support for FSKN development and delivery of programs. In addition, organizations such as the United Nations Industrial Development Organization (UNIDO) and the International Finance Corporation (IFC) of the World Bank Group have utilized FSKN-created materials in their own development projects that are focused on food safety capacity development in a number of countries. For the FSKN initiative, organizations such as UNIDO and IFC have been continuously engaged throughout the program. These collaborations have been critical to the successful implementation of FSKN and its dissemination to several economies outside the 
US.

Clearly, the FSKN initiative has engaged with and benefitted from this large number and variety of international partners. Each has been critical to the successful implementation of FSKN and dissemination of its content to beneficiaries in several economies.

\section{Individual level}

At the individual level, there has been a tremendous amount of networking among key individuals working for FSKN partner organizations. Although some of this networking and collaboration has occurred through events organized explicitly for FSKN development and implementation, a considerable amount of networking has occurred through other fora such as the Global Food Safety Initiative of the Consumer Goods Forum, the Partnership Training Institute Network of the Asia Pacific Economic Cooperation Forum, and the World Bank-organized Global Food Safety Partnership. This networking has involved a relatively small, yet highly influential, group of individuals who collaborate on FSKN and similar globally-focused initiatives in the area of food safety standards and food safety management systems implementation. This core network interacts less directly with beneficiary groups such as farmers or SME food processors, who typically have been identified for participation in the programs by their buying companies (e.g. multinational food corporations) or donor organizations such as UNIDO or IFC. Content delivery in FSKN-related projects has been conducted by a select group of highly-qualified experts working in academia (e.g. MSU), the food industry, or as consultants. In many cases, the same experts have been enlisted to implement training and capacity development programs by multiple food industry companies, associations or donor agencies. This highlights the need for engagement of more experts in networks such as FSKN, but also speaks to a relative dearth of recognized international experts in this specific discipline.

\subsection{In France: the ISO 22000 club launched by CCI Picardie}

In spring 2007, the Picardie region Chamber of Commerce and Industry (CCI) decided to launch for ten regional food companies (including Paris Caramel) an informal 'ISO 22000 club', a regional program to support ISO 22000 standards. This ISO 22000 program has consisted of business leader coaching along with accompanying collective actions for all participating companies. The Paris Caramel's management decided to embark on the process of certification because of new customers' requirements and changes in the business environment. The certification was not an absolute necessity for this profitable company but appears as a possible supplementary marketing asset, in accordance with the policy of sustainable customer satisfaction, by ensuring the safety of products sold. It would also eliminate the different and heterogeneous customers' specifications and create differentiation towards competitors. Ultimately, Paris Caramel attained ISO 22000 certification in October 2008.

Founded in 1957, Paris Caramel is a food SME located in the Picardie region in Northern France and manufactures chocolate and confectionery products. The company manufactures three main types of products of the highest quality: caramel, fruit pulp and chocolate, for a turnover of 900000 Euros per year. Their customers are pastry confectioners, delicatessens and shops selling local products. The company has forty employees, mainly makers of caramels, fruit jellies and chocolate candies. In 2000, the company decided to develop the certification of various stages of the production process, starting with Hazard Analysis and Critical Control Points (HACCP) certification. As a small family-owned company, with a mostly self-educated staff, Paris Caramel is very cost-efficient with a short decision process. Another important characteristic of the company is its human dimension: human capital is more important than financial returns, and the managers put more emphasis on training their employees and on maintaining employment than on profits. 


\section{Organizational level}

Continuous ties such as spatial (the location in the Picardie region, the role of the Regional Council) and cultural ties have been acknowledged by the company as important features, as they provide trust and easy communication. The tacit knowledge dimension of the standard is also to be considered: for that type of knowledge, considered as soft information, organizational proximity is sufficient. For the responsible person in charge of ISO 22000 implementation at Paris Caramel, the institutional embeddedness of the initiative, promoted both by AFNOR (French branch of ISO) and by the Chamber of Commerce, has played a crucial function in providing seriousness and credibility. The congruence of goals between all the stakeholders of the initiative, creating a specific relationship and a sense of responsibility, provided an environment for mechanisms such as emulation and mimicry. Indeed, these effects can be considered as learning effects as well, in reinforcing/auto-promoting the exchange of skills and information.

The learning by doing effects have been identified mainly between the consultancy firm and Paris Caramel: the role at that organizational level is significant at the initiation stage (establishment of a first contact and of a formal tripartite contract between the CCI, the consultancy firm and the company), but the main interaction effects have occurred at the individual level.

Organizations involved in the process of standard adoption are: AFNOR, CCI, consultancy firms, and other SMEs.

- The CCI (Chamber of Commerce and Industry) had no role in the definition phase. Its action is crucial in the adoption phase: the organization has acted as a pivotal organization between AFNOR, consultancy firms and SMEs, through defining the program funding and the setup of the tripartite contracts.

- Consultancy firm: Protechnic, a consulting firm, had a central role in the adoption stricto sensu phase. It is difficult to separate its role as a company and as a person. Indeed, the manager of the company has been largely convinced by the consultant to adopt the standard, however, the company also has very good experience and a reputation in working with SMEs. The specific expertise is the basis of the successful interaction process.

- ISO 22000 club for SMEs: this club is the heir of another previous club devoted to HACCP. Its role has been to connect companies from different industries (thus not in competition) to exchange views and questions about the standard and its consequences. Its role is both formal (membership) and informal (interpersonal relations, cf. below).

- Third party certifier: the certification body, Bureau Veritas, has conducted the certification process and has been the main player, with Paris Caramel, during the conformity assessment phase.

\section{Individual level}

The inter-individual aspects of the network learning effects are more difficult to evaluate for confidentiality reasons. Nevertheless, there is a clear complementarity of the continuous ties between the two levels, leading to strong coupling effects. The managers from Paris Caramel (the $\mathrm{CEO}$, the quality manager responsible) are part of a coherent community of leaders in the Picardie region and everybody knows each other quite well. This fact has played an important role in the decision to adopt. However, the individual level is also of tremendous importance for learning in terms of discrete ties and interactions (mainly with the consultant, but also with other food managers during the period of the CCI initiative as well as with some customers).

Informal contacts and exchanges may occur at any time and, for confidentiality and privacy reasons, interviewees are reluctant to answer. Nevertheless, interpersonal contacts seem to play an important role especially with one consultant and with all the managers from the ISO 22000 
group.

According to the analytical framework, the learning effects are different from one phase to another. We will consider successively the five main phases, namely standard setting (antecedents), decision of adoption, implementation stricto sensu, conformity assesment (certification), and enforcement (post certification).

During the standard setting phase, only limited network learning phenomena occurred, at the individual level, in the form of previous personal experiences of the quality manager of Paris Caramel in similar fields. Indeed, no formal contacts between the company and AFNOR had existed, showing that during its definition, the ISO 22000 standard does not include all potential users such as food SMEs.

The adoption decision is reached thanks to contact between the company and CCI: the learning effect can be defined as the rise of awareness of the company leaders involved in the initiative in the development of the standard and soft information exchange for the establishment of the tripartite contract.

The implementation phase is obviously the period of time (almost 2 years) that has witnessed important learning phenomena. Of course, from a financial point of view, it is not certain that two years will be sufficient to amortize the investment, which is why support from organizations and public bodies is necessary. The most important learning phenomena has occurred at the interindividual level, in the form of a strong interaction between the quality manager and the consultant in charge of the program. The formal explicit knowledge included in the ISO standard specifications necessitates adaptations and translations in the real world of the Paris Caramel specificities. On the contrary, formal contacts between organizations are limited during this period of time. Another significant network learning effect is the permanent contact between the food managers involved in the initiative, in terms of comparisons, informal exchange and emulation.

The conformity assessment phase is more formal: this is the recognition of compliance with the specification by means of a certification audit. The process of learning is done through an exchange of explicit information (such as files and information control procedures) between the company and the certifying body.

The enforcement phase is the post certification period of continous improvement. Learning effects occur mainly in-house, with the practical involvement of employees. Nevertheless, the informal contacts established during the implementation phase with other managers remain active, in the form of informal meetings, cross auditing practices and informal exchanges.

\section{Conclusion}

The objective of the article is twofold: (i) to propose an original framework, using a network effect perspective, for the analysis of the implementation of internationally-recognized food safety management systems (e.g. ISO 22000, GFSI-benchmarked food safety schemes); and (ii) to apply this framework to two case studies. The major motivation is the fact that the implementation of a FSMS is a long and complex process strongly related to its organizational and individual context. Quality management standards are immaterial in nature and difficult to implement: food SMEs and their managers will inevitably rely heavily upon collective initiatives (Ropkins \& Beck, 2000; Mensah \& Julien, 2011). The focus of this article is mainly food SMEs and one must acknowledge that this could create a bias in the results, as network effects have more consistency and accuracy in this specific context of small firms.

From this analysis, it is possible to summarize a few key features. At the preliminary stages of the implementation process, the learning effects do not extend outside the organizations. These effects occur more clearly during the implementation phase. The dynamic approach shows an interesting phenomena: in the latter phases of the implementation process (i.e. conformity and assessment phases), new types of partners emerge and their roles are of tremendous importance for the success of ISO 22000 adoption. It suggests that the position/relationships of the individual companies vis à vis these partners during that period of time must be clearly emphasized as a key component of the success of the initiative. For SMEs the interest of such initiatives is clearly 
to overcome strong limitations, not only in resource access, but also in cognitive gaps, as we have seen the importance of specific capabilities that must be developed at collective levels.

Preliminary results, still to be confirmed and extended to other cases, could have interesting managerial implications for food SMEs. First of all, the collective (i.e. network) dimension of the process is shown. No food SMEs in these initiatives could have decided in isolation to set up FSMS. Instead, the food companies of the case studies are strongly embedded in a web of partners, defining a networking activity for innovation. Within this network, the process of learning is doubly collective: at the institutional level, where institutions, (e.g. Chamber of Commerce and Industry, academic institutions), consultancy firms and associations (e.g. AFNOR, GFSI) have worked together to promote the initiatives; at a micro-analytic level, with the SMEs building strong relationships with service providers (e.g. consultancy firms, certification bodies) and, at the same time with a broader community of food business leaders having its own dynamics, objectives and social interaction mechanisms. One must also acknowledge the fact that this process is not one-sided: consultancy firms themselves, as well as probably other partners, adapt to the situation and improve their own knowledge in such processes.

A second idea is that of resources. The critical success factor in FSMS implementation by SMEs in these case studies seems not to be financial resources, but rather access to cognitive resources, (i.e. the ability to connect and to be connected through a web of relationships to the relevant people and organizations). Learning phenomena appear to be complex, multifaceted and done through several mechanisms and mediation. Consequently, an important managerial implication of the research, to be validated by other situations and countries, would be to enhance these cognitive resources and mechanisms, to identify more precisely their nature, the partners involved and their roles for learning in relation with the requirements of the different phases of implementation.

For the Picardy Food Safety Club, the cognitive effects of this initiative have been limited: no real creation of common memory, no identifi- cation and formalization, inside the network, of codified knowledge related to ISO 22000 implementation. This knowledge has mainly remained at the consultant level, without significant socialization and embeddedness at an upper level. For this particular case it seems that the main benefits of the initiative have been in the mimicry phenomena and socialization around the interests of food safety standards such as ISO 22000 that has led to a strong involvement and motivation of the concerned companies.

In the case of the FSKN initiative in the USA and other countries, the focus on a standardized, competency-based approach to capacity development linked to a concrete framework (the GFSI Global Markets Programme) provided a consistent framework for SME development. The use of open education resources within the network encouraged partner organizations to adapt, localize and share derivative training content in multiple countries and in several languages.

\section{Acknowledgements}

This project was supported in part by Agriculture and Food Research Initiative Competitive Grant no. 2011-51110-31104 from the United States Department of Agriculture (USDA) National Institute of Food and Agriculture. The project has also received funding from the European Union Seventh Framework Programme (FP7/2007-2013) under grant agreement $\mathrm{n}^{\circ} 245301$, as a part of the project "Enhancing the innovativeness of food SME's through the management of strategic network behavior and network learning performance" coordinated by Ghent University.

\section{References}

Abdirahman, Z.-Z., Kisempa Muyuala, G., \& Sauvée, L. (2013). Mapping formal networks and identifying their role for innovation in EU food SMEs. In G. W. Schiefer \& J. Deiters (Eds.), (Chap. France: Case studies 3D Network, ARI Picardie and BioBourgogne, pp. 67-88). Bonn: Centmapress. 
Abdirahman, Z.-Z. \& Sauvée, L. (2012). The implementation of a quality management standard in a food sme: a network learning perspective. International Journal on Food System Dynamics, 3(3), 214-227. doi:10 . 18461/ijfsd.v3i3.333

Argyris, C. \& Schön, A., Donald. (1996). Organizational Learning II: Theory, Method, and Practice. Reading: Addison-Wesley.

Borgatti, S. P. \& Li, X. (2009). On social network analysis in a supply chain context. Journal of Supply Chain Management, 45(2), 5-22. doi:10.1111/j.1745-493X.2009.03166.x

Boris, B., Sandra, C. P., \& Isabelle, H. (2007). Réseaux sociaux et processus d'apprentissage, une relation complexe et ambivalente. In Communication à la 16ème conférence de l'aims (Vol. 6). Retrieved from https://basepub.dauphine.fr/handle/ $123456789 / 2261$

Burt, R. S. (2000). The network structure of social capital. In Research in organizational behavior, vol 22, 2000 (Vol. 22, pp. 345423). Research in Organizational Behavior. doi:10.1016/S0191-3085(00)22009-1

Conway, S., Jones, O., \& Steward, F. (2001). Social interaction and organizational change: aston perspectives on innovation networks', series on technology management. In F. Oswald Jones Steve Conway \& Fred Steward (Ed.), In social action and organisational change: aston perspectives on innovation networks, eds (Chap. Realizing The Potential Of The Network Perspective, Vol. 6, 11, pp. 349-366).

Conway, S. \& Steward, F. (1998). Mapping innovation networks. International Journal of Innovation Management, 02(02), 223-254. doi:10 . 1142 / S1363919698000110. eprint: https://www.worldscientific.com/doi/pdf/ $10.1142 / \mathrm{S} 1363919698000110$

Conway, S. \& Steward, F. (2009). Managing and shaping innovation. Oxford University Press.

Coulon, F. (2005). The use of social network analysis in innovation research: a literature review "lund university". Sweden. Retrieved from http : / / gent . uab. cat / diego_prior/sites/gent.uab.cat.diego_prior/ files/Article_to_comment_10_bis.pdf
Dierkes, M., Antal, A. B., Child, J., \& Nonaka, I. (Eds.). (2003). Handbook of organizational learning and knowledge. New York, NY, USA: Oxford University Press, Inc.

Eisenhardt, K. M. \& Graebner, M. E. (2007). Theory building from cases: opportunities and challenges. Academy of Management Journal, 50(1), 25-32. doi:10.5465/AMJ . 2007.24160888

Geith, C., Vignare, K., Bourquin, L., \& Thiagarajan, D. (2010). Designing corporate training in developing economies using open educational resources. Online Learning, 14(3). doi:10.24059/olj.v14i3.142

Hatanaka, M., Bain, C., \& Busch, L. (2005). Third-party certification in the global agrifood system. Food Policy, 30(3), 354-369. doi:10.1016/j.foodpol.2005.05.006

Hatanaka, M., Bain, C., \& Busch, L. (2006). Differentiated standardization, standardized differentiation: the complexity of the global agrifood system. In Between the local and the global (pp. 39-68). doi:10.1016/S10571922(06)12003-X

Henson, S. \& Humphrey, J. (2009). The impacts of private food safety standards on the food chain and on public standard-setting processes. Joint FAO/WHO Food Standards Programme, Codex Alimentarius Commission, Thirty-second Session, FAO Headquarters, Rome, 29. Retrieved from http: //www.fao.org/tempref/codex/Meetings/ CCEXEC/ccexec64/ex64_04e.pdf

Henson, S. \& Humphrey, J. (2010). Understanding the complexities of private standards in global agri-food chains as they impact developing countries. Journal of Development Studies, 46(9), 1628-1646. doi:10.1080/ 00220381003706494

Heyboer, G., Kim, S., Bourquin, L. D., \& Thiagarajan, D. (2010). Building capacity in developing countries: oer for food safety. Universitat Oberta de Catalunya. Retrieved from https://oerknowledgecloud.org/sites/ oerknowledgecloud.org/files/Heyboer.pdf

Inkpen, A. C. \& Tsang, E. W. K. (2005). Social capital, networks, and knowledge transfer. Academy of Management Review, 30(1), 146-165. doi:10.5465/AMR.2005.15281445 
Levitt, B. \& March, J. G. (1988). Organizational learning. Annual Review of Sociology, 14, 319-340. doi:10.1146/annurev.so. 14.080188 .001535

Mensah, L. D. \& Julien, D. (2011). Implementation of food safety management systems in the uk. Food Control, 22 (8), 1216-1225. doi:10.1016/j.foodcont.2011.01.021

Nahapiet, J. \& Ghoshal, S. (1998). Social capital, intellectual capital, and the organizational advantage. Academy of Management Review, 23(2), 242-266. doi:10.2307/259373

Owen-Smith, J. \& Powell, W. W. (2004). Knowledge networks as channels and conduits: the effects of spillovers in the boston biotechnology community. Organization Science, 15(1), 5-21. doi:10.1287/ orsc. 1030.0054

Pawlowsky, P. (2001). The treatment of organizational learning in management science. Handbook of organizational learning and knowledge, 61-88.

Pitsis, T. (2013). Handbook of organizational and managerial innovation. Elgar original reference. Edward Elgar Publishing, Incorporated. Retrieved from https:// books . google.pt/books?id=TjTiTqP9zPsC

Pittaway, L., Robertson, M., Munir, K., Denyer, D., \& Neely, A. (2004). Networking and innovation: a systematic review of the evidence. International Journal of Management Reviews, 5-6(3-4), 137-168. doi:10 . $1111 /$ j.1460-8545.2004.00101.x

Podolny, J. M. \& Page, K. L. (1998). Network forms of organization. Annual Review of Sociology, 24, 57-76. doi:10.1146/annurev. soc.24.1.57

Powell, W. W., White, D. R., Koput, K. W., \& Owen-Smith, J. (2005). Network dynamics and field evolution: the growth of interorganizational collaboration in the life sciences. American Journal of Sociology, 110(4), 1132-1205. doi:10.1086/421508

Powell, W. W., Koput, K. W., \& Smith-Doerr, L. (1996). Interorganizational collaboration and the locus of innovation: networks of learning in biotechnology. Administrative science quarterly, 116-145.

Ropkins, K. \& Beck, A. J. (2000). Evaluation of worldwide approaches to the use of haccp to control food safety. Trends in Food Science $\&$ Technology, 11(1), 10-21. doi:10. 1016/S0924-2244(00)00036-4

Scott, V. N. \& Chen, Y. (2010). Pathogens and toxins in foods: challenges and interventions. In V. K. Juneja \& J. Sofos (Eds.), (Chap. Food Safety Management Systems, pp. 477-492). Washington: ASM Press.

Trienekens, J. \& Zuurbier, P. (2008). Quality and safety standards in the food industry, developments and challenges. International Journal of Production Economics, 113(1), 107-122. doi:10.1016/j.ijpe.2007.02.050

Yin, R. K. (2013). Validity and generalization in future case study evaluations. Evaluation, 19(3), 321-332.

Zheng, W. (2010). A social capital perspective of innovation from individuals to nations: where is empirical literature directing us? International Journal of Management Reviews, 12(2), 151-183. doi:10.1111/j.14682370.2008.00247.x 